Title: Correlates of Caregiving Burden in Schizophrenia: A Cross-sectional, Comparative Analysis from India

\title{
Authors
}

Selwyn Stanley, $\mathrm{PhD}$

Faculty of Education, Health \& Wellbeing, University of Wolverhampton, Wolverhampton, UK

Sujeetha Balakrishnan, $\mathrm{PhD}$

Thanjavur Medical College, Thanjavur, India

S. Ilangovan, MD

Thanjavur Medical College, Thanjavur, India

Address correspondence to: Selwyn Stanley. E-mail: Email: selwyn.stanley@wlv.ac.uk 


\begin{abstract}
Schizophrenia is a global mental health issue that has serious implications not only for the person with the diagnosis, but for caregivers as well. In Asian societies, the family tends to be the 'natural' caregiver in such situations and is usually shouldered by parents or the spouse. Asian communities tend to be more closely knit and it would be expected that more social support would be available to those facing distressing circumstances such as managing the demands of a person with mental illness. This study seeks to explore the perceived burden in family caregivers of persons diagnosed with schizophrenia, the coping strategies that come into play as well as the extent of social support available to them. Standardised instruments were administered to collect data at a teaching cum treatment facility in south India. A quantitative methodology was used to analyse cross-sectional data from 75 primary caregivers of people with a diagnosis of schizophrenia and a reference group of caregivers of patients with general medical ailments. Results indicate high levels of burden, low social support and poor coping in the caregivers of people with schizophrenia than the reference group. Implications for intervention with caregivers have also been discussed in this article.
\end{abstract}

Key words: caregiving burden; coping; social support; schizophrenia, mental illness. 


\section{Correlates of Caregiving Burden in Schizophrenia: A cross-sectional, comparative analysis from India}

\section{Introduction}

Schizophrenia affects more than 21 million people worldwide (World Health Organisation, 2016). Studies from India have suggested that the prevalence of schizophrenia is lower than in the West (Math, Chandrashekar \& Bhugra (2007). While this may well be so, given the large size of the general population, the number of persons with schizophrenia is enormous. Asian studies show that about $70 \%$ of people with schizophrenia live with their family and depend on family members for the provision of care (Chan \& Yu, 2004; Sethabouppha \& Kane, 2005).

Schizophrenia in general and the issue of caregiving is a topic that has been widely researched worldwide. Rightly so, as it has far reaching consequences for caregivers across various domains that involve financial, emotional and social components. In both developed and developing countries, the issue of family burden in caring for people with schizophrenia is a common challenge (Chan, 2011). Zarit, Todd and Zarit (1986) have defined burden as the extent to which caregivers perceived their emotional and physical health, social life and financial status as suffering as a result of caring for their relative. The literature on caregiving burden differentiates between objective and subjective burden (Awad \& Voruganti, 2008). Objective burden is associated with the patient's symptoms, behaviour, and factors such as changes in household routine, family or social relations, work, leisure time, and physical health, while subjective burden is the adverse impact on the mental health and subjective distress experienced by family members (Reine, Lancon, Simeoni, Duplan, \& Auquier, 2003). Studies from India have shown that caregivers of persons with severe mental 
illness show symptoms of depression, anxiety and stress (Stanley, Mettilda, \& Bhakyalakshmi, 2015; Janardhana, Raghunandan, Naidu, Saraswathi, \& Seshan, 2015).

Family members are significantly distressed when one of the members is afflicted by schizophrenia (Martens \& Addington, 2001). Caregiving strain is frequently associated with consequences such as depression, burn out and other forms of psychological distress (Magliano, Fiorillo, De Rosa, Malangone, \& Maj, 2005). Caregiving burden, especially tension is associated with the use of maladaptive coping strategies, poor quality of life and higher level of psychological morbidity in caregivers of patients with schizophrenia (Kate, Grover, Kulhara, \& Nehra, 2013). Studies conducted in India have found that burden is experienced in the form of disruption in family life and interactions, financial burden, wellbeing and health (Thara, Padmawati, Kumar, \& Srinivasan, 1998; Talwar \& Matheiken, 2010). Disruption of family activities is an important area that contributes to heightened burden, as caregivers have to spend a significant amount of their time that not only interferes with their own routine, but also affects the needs of other family members (Prafulla, Murthy, \& Ramaprasad, 2010). Caregivers have reported lacking time for themselves and for their other responsibilities (e.g., family and work) and adversely impacting their physical (e.g., fatigue, sickness) and emotional well-being (e.g., depression and anxiety) (Gater et al., 2014). Burden has been associated with caregiver fatigue, restricted activities, financial constraints, and costs (Rose, Mallinson, \& Gerson, 2006).

In most cultures particularly Asian and Oriental communities the caregiving burden is usually experienced by the family, which is considered to be the 'natural' primary caregiver. The issue of family burden assumes significance in India as the majority of patients with schizophrenia stay with their families (Thara et al., 1998; Murthy, 2006). Studies from India 
about caregiving burden in severe mental illness have indicated high burden in caregivers (Ampalam, Gunturu, \& Padma, 2012; Stanley et al., 2015). The scenario varies across cultures in terms of issues such as available social support, associated stigma and how the illness is perceived in general and dealt with. Often families experience significant discrimination due to mental illness and burden (Thara, Kamath, \& Kumar, 2003). Marriage, fear of rejection by neighbours and the need to hide the illness from others are some of the more stigmatizing aspects of mental illness in the Indian context (Thara \& Srinivasan, 2000). Cultural characteristics may account for differences in caregiver burden as cultures may differ in their appraisal of mental illness, ranging from acceptance and social integration to stigmatization; beliefs about the origin of mental illness, beliefs rooted in religion and society's appraisal of the caregiver's role (van Wijngaarden et al., 2003).

The issue of coping becomes important in the context of burden experienced by caregivers. However this has not been as extensively explored like the issue of caregiver burden, particularly in the literature from India. Little is known in developing countries about the ways in which families cope while caring for one of their members who has schizophrenia (Chandrasekharan, Sivaprakashz, \& Jayestri, 2002). Several instruments have been used to investigate this domain and this accounts for the variation in terminology found in the literature on caregiving coping and makes comparison of results difficult. An earlier study from India (Creado, Parkar, \& Kamath, 2006) has found that fatalism and problem solving were the two most preferred ways of coping. While problem focused coping, i.e. problem solving and expressive action decreased the burden of caregivers, emotion focused coping, i.e. fatalism and passivity, increased it. As the level of functioning of the patient decreased, the significance with which the coping mechanisms influenced the burden, increased. The use 
of problem solving coping by caregivers showed a significant correlation with higher level of functioning in patients (Creado et al., 2006).

A major issue of concern in terms of having a family member with schizophrenia relates to supportive social networks that are available to the family (Caqueo-Urízar, Miranda-Castillo, Giráldez, Maturana, Pérez, \& Tapia, 2014). Evidence from different countries indicates that generally there is inadequate help and support for the family caregivers (Chan, Yip, Tso, Cheng, \& Tam, 2009). Understanding the sociocultural context is important as it influences not only perceived burden, but also cultural construction and ways of coping with mental illness, in addition to social and family networks and supports (Guarnaccia \& Parra, 1996; Jenkins \& Schumacher, 1999). Also the coping strategies used by the caregivers and available the social support available to them influences their final appraisal of caregiving (Aggarwal, Avasthi, Kumar, \& Grover, 2011). A supportive social network has been reported in relatives with low levels of burden and pessimism about schizophrenia (Magliano, Fiorillo, Malangone, Marasco, Guarneri, \& Maj, 2003). Studies also indicate that family support was positively related to higher levels of family functioning (Saunders, 1999) and a low level of social support has been found to be strongly associated with higher scores in need assessments and more unmet needs (Caudle, 1993).

The dominant conceptual model for caregiving assumes that the onset and progression of chronic illness are stressful experiences for the patient as well as the caregiver and so the framework of stress-coping models can be used to study caregiving burden (Shulz \& Sherwood, 2008). We subscribe to this contention and have used the stress-coping framework in this study. We see the patients' symptoms, duration of illness, problem behaviours and other illness related factors, besides the extent of social support and the efficacy of coping as contributing to the burden experienced by caregivers. This study was framed against this 
background to assess the extent of burden, nature of coping and social support available to caregivers of people with Schizophrenia. An assessment of the nature of symptoms of the person with schizophrenia has also been done.

\section{Methods}

\section{Research objectives}

1. To assess the nature of symptoms manifest in people with schizophrenia.

2. To compare the extent of burden, nature of coping and social support available to the primary caregivers of people with schizophrenia and those with general medical conditions.

3. To compare both groups of caregivers on the key variables based on select sociodemographic factors.

4. To determine the nature of correlation between the various variables of the study in caregivers of people with schizophrenia.

5. To identify factors which contribute to the burden perceived by the caregivers of people with schizophrenia.

\section{Instruments}

1. Self-prepared schedule to collect background information.

2. The Positive and Negative Syndrome Scale (PANSS) by Kay, Fiszbein, and Opler (1987). The PANSS was developed based on findings that schizophrenia comprises of at least two distinct syndromes. The positive syndrome consists of symptoms such as delusions, conceptual disorganization, hallucinations, hyperactivity, grandiosity, suspiciousness and hostility and forms the positive subscale. The negative syndrome consists of deficit 
features such as blunted affect, stereotyped thinking, emotional withdrawal. It is a 30 item instrument of which 7 items constitute the Positive Scale, 7 items the Negative Scale, and the remaining 16 a General Psychopathology Scale (symptoms such as anxiety, depression, guilt). The scores for these scales are arrived at by summation of ratings across component items that are rated from 1 to 7 according to symptom severity from 1 for 'absent' to 7 for 'extreme'. This instrument was administered only to the person with schizophrenia.

3. The Zarit Burden Interview (ZBI) by Zarit, Reever, and Bach-Peterson (1980), a popular caregiver self-report measure and contains 22 items. Each item on the interview is a statement which the caregiver is asked to endorse using a 5-point scale. Response options range from 0 (Never) to 4 (Nearly Always). A cumulative burden score has been used in this study. Though the instrument was initially developed to assess caregiver burden in dementia, it has been used extensively in relation to mental illness (e.g. Hanzawa et al., 2010) and has undergone extensive testing for cross-cultural applicability (Chakrabarti, 2016). It has been extensively used in India to explore caregiving burden in different groups such as cancer patients (Lukhmana et al., 2015); hearing impairment (van Driessche et al., 2014); stroke (Issac et al., 2011) and elderly people (Brinda et a., 2014).

4. Family Crisis Oriented Personal Scales (F-COPES) by McCubbin, Olson, and Larsen (1991), identifies problem solving and behavioural strategies used by families when faced with problems or crises. The scale has 30 items that describe a variety of coping behaviours that individuals may use in times of stress or crisis. The respondent rates the items on a 1-5 scale with 1 for 'Strongly disagree', and 5 for 'Strongly Agree'. The instrument assesses five domains namely: Acquiring social support, Reframing, Seeking Spiritual Support, Mobilizing to acquire and accept help and Passive appraisal. 
5. Social Provisions Scale (SPS) by Cutrona and Russell (1987) is used to examine the degree to which respondent's social relationships provide various dimensions of social support. The instrument contains 24 items, four for each of the following domains: Attachment, Social Integration, Reassurance of Worth, Reliable Alliance, Guidance, and Opportunity for Nurturance. Half of the items describe the presence of a type of support and the others describe the absence of a type of support. The respondent indicates on a 4point scale the extent to which each statement describes his/her current social network. Responses range from 1 (strongly disagree) to 4 (strongly agree). A high score indicates a greater degree of perceived support.

\section{Setting of the study}

Thanjavur (also known as Tanjore) is a temple town in Tamilnadu state in South India. It is renowned for the famous Brihadeeswara Temple, constructed in the $11^{\text {th }}$ century and is a world heritage site declared by the UNESCO. Data for the study was collected at the Thanjavur Medical College Hospital which is a multi-speciality teaching cum treatment center established in 1964. It has a bed strength of 678 and caters to patients predominantly from the adjoining rural districts. It offers treatment in 18 specialisms including the department of Psychiatry, where data for this study was collected.

\section{Data collection}

Data was collected from two groups of caregivers $(n=75$, each). The study group consisted of 75 caregivers of patients diagnosed (according to ICD-10) and undergoing treatment for schizophrenia as inpatients in the department of Psychiatry of the Medical College. The caregivers of patients with a diagnosis of schizophrenia were contacted on a consecutive basis as they registered the patient for treatment. Those with comorbidity (dual diagnosis) 
were excluded. No sampling procedure was used. The PANSS was administered to the person undergoing treatment to determine the nature of their symptoms and the remaining instruments to the caregivers.

The second group (comparative/reference group) involved caregivers of patients undergoing treatment for general medical conditions (such as pains, diarrhoea, fever-hitherto referred as GMC patients). Patients consecutively approaching the hospital for treatment were included and those with chronic illnesses (such as HIV, diabetes, cancer) were excluded. It was felt that the inclusion of such a group was necessary to ascertain if the caregivers of people with schizophrenia could be statistically differentiated from the reference group on the key variables of this study. All instruments administered to the caregivers of the study group were also administered to the reference group.

Data was collected over a 12 month period from Feb 2015 to Jan 2016. The study received ethical clearance from the ethics review panel of the institution. The caregivers were briefed about the nature of the study and assured of anonymity and confidentiality. Participation was voluntary and informed consent was obtained from them and they were told that they had the option to drop out of the study at any stage without any implications in terms of the treatment being availed by their family member.

\section{Statistical analysis}

SPSS (Statistical Package for Social Sciences; SPSS Inc., Chicago, USA) version 20 was used for data analysis and for generating the results of this study. $t$ tests were used to differentiate caregivers of patients with schizophrenia from the reference group and also to compare the manifestation of the key variables according to the gender of the patients and 
their caregivers. One way analysis of variance (ANOVA) was used to compare mean scores for patients of different age groups as also their relationship to the caregiver. Pearsons correlation coefficients were used to examine the relationship among the key variables and also with certain background factors such as age and duration of illness. A multiple regression analysis using the enter method was finally executed to identify predictor variables that influence the manifestation of caregiver burden.

\section{Results}

\section{Insert Table 1 here}

\section{Background profile of respondents}

Study group: They were all married and the majority of caregivers in this study were men. In keeping with the demographics of the area, the majority were Hindus and were farmers. They had a very low educational level, came from a rural background and had been to school at different levels, but not beyond. The family size for the majority was 2 to 4 members with a mean family size of 3.63 and their monthly income was up to Rupees four thousand (approx. $\$ 60)$. In terms of their relationship to the patient, the majority were parents and the next category was the spouse.

The patients undergoing treatment had a mean age of 31.4 (range 17 to 54) and the majority were men $(63.6 \%)$ and were unmarried (59.7\%). They had a low level of education at different levels of school and $45.5 \%$ were unemployed and $18.2 \%$ were housewives. The others in this study were farmers, tailors, weavers, mechanics and engaged in small trades. 63.6\% did not have an income and those who did, earned up to Rupees three thousand per 
month (about \$45). The duration of their illness ranged from 5 to 15 years with a mean of 5.67. They had all been in treatment previously and mentioned that the illness had an insidious onset and that it was progressive in nature with deterioration of symptoms over time.

Reference group: Like the study group respondents these caregivers were also all married, the majority being men. The majority were Hindu farmers. They also had a very low level of education and came from a rural background with different levels of education at school level. The family size for most of them was 2 to 3 members with a monthly income up to Rupees four thousand. With regard to the relationship with the patient the majority were parents and the remaining were spouses. The profile of both groups of caregivers shows that they were similar and comparable on basic sociodemographic variables.

\section{Insert Table 2 here}

\section{PANSS profile of people with a diagnosis of schizophrenia}

Table 2 depicts the PANSS prof Insert Table 2 here sis of schizophrenia. When compared to the other two domains of the PANSS, people with schizophrenia had relatively low scores in terms of positive symptoms as the majority have scored up to 30 (maximum score 49). The negative symptom scale in the PANSS include blunted affect, emotional withdrawal, poor rapport, apathetic social withdrawal, difficulty in abstract thinking, lack of spontaneity and stereotyped thinking. While the scores for this scale are distributed at all levels, the majority of respondents have scored up to 40 (out of a potential 49). The 16 general and global items measure symptoms like anxiety, tension, mannerism, unusual thought contents, disorientation etc. and constitute the general psychopathology scale. The majority have scored between 31 and 50 (maximum score 112) on this scale. 


\section{Comparison of both groups on key study variables}

Student $\mathrm{t}$ tests were conducted to identify if there was any significant statistical difference between both groups on the key variables of this study. The results are depicted in Table 3 and show a highly significant statistical difference on the burden scores $(\mathrm{p}<.001)$, the FCopes and all its domains $(\mathrm{p}<.001)$ as well as the SPS $(\mathrm{p}<.001)$ and its domains (except for 'attachment' $\mathrm{p}<.01)$. The mean scores when compared show a very high burden score for the caregivers of people with schizophrenia than the reference group. In terms of the coping scale and the social provisions scale the mean scores are higher for the GMC caregivers than the study group, showing better coping and greater social support for them than for caregivers of people with schizophrenia.

\section{Insert Table 4 here}

\section{Comparison based on caregivers' status (parent/spouse)}

For this analysis the caregivers were re-classified as parents and spouses and then compared on the key variables. We first conducted a oneway analysis of variance (ANOVA) for the total scores of the three scales comparing parents and spouses for the study and reference groups (Table 4). The results show a significant difference between these four groups of caregivers on all three scale total scores. On the ZBI, the mean scores were highest for spouses in the study group (84.78) than for parents (81.72) and lowest for parents in the reference group (19.26) as against spouses (20.46). This indicates higher burden experienced by caregivers of people with schizophrenia than those with general medical ailments. Among the caregivers of the schizophrenia group, spouses perceived greater burden than parental caregivers. For the F-COPES total score, the highest mean was for spouses in the reference group (94.69) as against parents (91.90) and lower for parents in the study group (59.53) than spouses (61.61). This shows better coping in reference group caregivers than those in the 
study group and among them for spouses than parents. For the SPS total scores, the highest mean was for spouses in the reference group (60.00) and lowest for spouses in the study group (46.89), indicating higher social support for caregivers in the reference group. For the study group caregivers, parents received higher social support than spouses.

The data in the following sections is based only on the study group respondents (caregivers of people with schizophrenia, $n=75$ ) who are the primary focus of this study.

\section{Insert Table 5 here}

\section{Comparison of caregivers based on median scores}

In this analysis, the caregivers were reclassified into low and high categories based on the median score for each scale. The data in Table 5 shows that the majority of caregivers have been classified as being 'low' in terms of coping and social support and 'high' in terms of burden experienced.

\section{Comparison of caregivers based on their age}

Caregivers were reclassified into four groups based on their age (20 to 30; 31-40; 41-50 and 51-60). A oneway analysis of variance (ANOVA) was then executed in terms of the total scores of the F-Copes, SPS and ZBI. The resulting F values were not significant $(\mathrm{F}=.99, .77$ and .45 respectively; $p>.05)$ showing that coping, social support and burden experienced did not differ according to the age of the caregivers.

\section{Comparison of caregivers based on their gender}


$t$ tests carried out based on the gender of the caregivers however did not yield any significant statistical difference in terms of either the total F-Copes score $(t=1.68 ; p>.05)$, the total SPS score $(\mathrm{t}=.47 ; \mathrm{p}>.05)$ or the ZBI score $(\mathrm{t}=1.62 ; \mathrm{p}>.05)$.

\section{Comparison of caregivers based on the age of the patients}

For this analysis the age of the patients were re-categorised into four groups (15-25; 26-35; 36-45; 46-55) and caregivers then compared on their F-Copes, SPS and ZBI scores using one way ANOVA. It was seen that a significant statistical difference was manifest only for the SPS scores $(\mathrm{F}=3.25 ; \mathrm{p}<.05)$.

\section{Comparison of caregivers based on the gender of the patients}

Caregivers were then compared on the key variables in terms of the gender of the person diagnosed with schizophrenia, whom they were responsible for. $t$ tests revealed no significant difference on the total F-Copes, SPS and ZBI scales. Significant difference was seen only in terms of the seeking spiritual support sub-dimension of the F-Copes $(t=2.39 ; p<.05)$ for which a higher mean was obtained for female patients (8.4) as against male patients (8.1).

\section{Comparison of caregivers based on the marital status of the patients}

The next $\mathrm{t}$ test compared the caregivers on the key variables in terms of the marital status of the patients. $\mathrm{t}$ tests did not obtain any significant statistical difference in terms of the total scores of all three scales. The only significant difference was seen with regard to the 'reassurance of worth' $(\mathrm{t}=2.12 ; \mathrm{p}<.05)$ sub-dimension of the SPS.

\section{Insert Table 6 here}

\section{Correlations among key variables (caregivers-study group)}

Significant positive correlations were obtained between the total F-Copes score and the general psychopathology score of the patient as well as the total SPS and ZBI scores (Table 
6). Of the domains of the F-Copes, reframing of the caregiving situation $(r=.33 ; p<.01)$ and passive appraisal $(\mathrm{r}=.47 ; \mathrm{p}<.01)$ of it were positively related to the burden scores while mobilising family resources related negatively $(\mathrm{r}=-.46 ; \mathrm{p}<.01)$.

The negative symptoms correlated negatively with the positive symptom scores, and positively with the general psychopathology scores and the total SPS scores. The general psychopathology scores showed a significant positive correlation with the total F-Copes scores.

The total SPS scores showed a significant negative correlation with the negative symptoms and the total ZBI scores and positively with the F-Copes scores. In terms of the domains of social support, reassurance of worth $(\mathrm{r}=-.31 ; \mathrm{p}<.001)$ and guidance $(\mathrm{r}=-.24 ; \mathrm{p}<.05)$ showed significant negative relations while opportunities for nurturance $(r=.24 ; \mathrm{p}<.05)$ related positively with the burden scores.

\section{Predictors of caregiver burden-study group}

The ZBI scores were treated as the dependent variable and a multiple regression analysis was performed for the caregivers of the study group $(n=75)$. The independent variables were the total F-Copes score, total SPS score and the positive, negative and general psychopathology scores of the PANSS, the size of the family, the patient's and their caregiver's age, as well as the duration of illness. Using the enter method it was found that the ANOVA was significant $(\mathrm{F}(9,65)=2.61 ; \mathrm{p}<.05)$ and that together the independent variables explained a significant amount of the variance in the extent of burden experienced $\left(\mathrm{R}^{2}=.27, \mathrm{R}^{2}\right.$ Adjusted $\left.=.16\right)$. The FCopes $(\beta=.22, \mathrm{t}(65)=1.89, \mathrm{p}<.05)$ and SPS scores $(\beta=-.29, \mathrm{t}(65)=2.44, \mathrm{p}<.05)$ were the only two key variables that significantly predicted the burden experienced by the caregivers. 
With regard to the socio-demographic variables entered into the analysis only the size of the family emerged as a significant predictor $(\beta=-.39, \mathrm{t}(65)=3.07, \mathrm{p}<.01)$. The results showed that positive symptoms $(\beta=-.12, \mathrm{t}(65)=.69, \mathrm{~ns})$, negative symptoms $(\beta=-.18, \mathrm{t}(65)=.90$, $\mathrm{ns})$ and general psychopathology scores $(\beta=.15, \mathrm{t}(65)=1.07, \mathrm{~ns})$ did not significantly predict burden experienced by the caregivers. Also the age of the patients $(\beta=.09, \mathrm{t}(65)=$ $.63, \mathrm{~ns})$ and their caregivers $(\beta=.04, \mathrm{t}(65)=.36, \mathrm{~ns})$ as well as the duration of illness $(\beta=$ $.01, \mathrm{t}(65)=.02, \mathrm{~ns})$ were not significant predictors in the regression model.

\section{Discussion}

The PANSS profile of the patients shows that the majority had a predominance of positive than negative symptoms. This could make them less stable, aggressive and hostile, with suicide attempts or self-mutilation and consequently they are brought in quicker for treatment as their behaviour tends to be dangerous and disturbing and requires hospital admission (Razali \& Hariani, 2015). Several studies have reported an association between symptom severity and caregiver burden (e.g. Gulseren et al., 2010). However studies that have used the PANSS have generated mixed results. A few studies have reported a positive relationship between PANSS scores and caregiver burden (e.g. Adeosun, 2013; Ponangi, Thatisetti, \& Dronanmraju, 2014). While some studies have reported that both positive and negative symptoms are independently correlated with caregiver burden (e.g. Schene, van Wijngaarden, \& Koeter, 1998; Wong, 2000), others have reported that positive (Gülseren et al., 2010; Wolthaus et al., 2002) or negative symptoms (Ukpong, 2012; Provencher \& Mueser, 1997) heighten caregiver burden. In this study no correlations were obtained between any of the three PANSS scales or its total score and caregiver burden. Nor have they been elicited as predictors of caregiving burden through the regression analysis. 
The sociodemographic profile of respondents in this study matches that of another study from India which reported that the mean age of the patients was about 31 years, more than half of them were male and the majority of them were unemployed and Hindu by religion (Kate et al., 2013). In terms of gender, the majority of caregivers in this study were men. This does not conform to the notion that caregivers are more likely to be women in many parts of the world. For example, in the United Kingdom, about $58 \%$ of the caregivers were women (Nolan, 2001) and other Asian studies have reported that about $70 \%$ of family caregivers were female (Chan et al., 2009; Cheng \& Chan, 2005).

The results of this study show that in comparison with caregivers of people with general medical conditions, caregivers of people with schizophrenia show very high levels of burden, and have lesser social support and show lower coping across several domains. Similar to this investigation, another comparative study from India has reported higher burden scores for those who care for people with mental illness than for those caring for people with a chronic medical illness (Ampalam et al., 2012). The finding of high burden in caregivers is in consonance with the Western literature on this issue (Roick, Heider, Toumi, \& Angermeyer, 2006; Lowyck et al., 2004; Wolthaus et al., 2002) as well as studies from India (Mandal, Prakash, \& Sagar, 2014; Kate et al., 2013; Ampalam et al., 2012; Ganguly, Chadda, \& Singh, 2010). Disruption in several areas such as of routine family activities, family leisure and of family interaction besides its adverse effect on physical and mental health of others has been reported in families having a person with schizophrenia (Lasebikan \& Ayinde, 2013). 
This study indicated greater burden in spouses of patients than their parents and these results are not in consonance with the Western literature that suggests that parents perceive more burden than spouses (Caqueo-urizar, Gutierrez-Moldonado, \& Miranda-Castillo, 2009). However, these findings are in accordance with other Indian studies (Kate et al., 2013; Rammohan, Rao, \& Subbakrishna, 2002; Jayakumar, Jagadheesan, \& Verma, 2002) which report greater burden in spouses than parents. Cultural norms dictate that the spouse (particularly the wife) is devoted to the care of an ill person and they are expected to take care and attend to all the needs and demands of their partner.

Previous studies from India indicate that caregiver burden is higher when the patient is male, caregiver is female, caregiver is less educated and in those from a low-socioeconomic background (Nehra, Chakrabarti, Kulhara, \& Sharma, 2005; Kumar \& Mohanty, 2007; Chakrabarti, 2010). While this study did not find that the perception of burden differed according to the gender of the caregiver or the patient, it was seen that both the patients as well as their caregivers came from a low economic and educational background. A review of the caregiving literature (Awad \& Voruganti, 2008) mentions that several studies that have examined the role of gender, have reported that relatives of male patients with schizophrenia frequently experience more social dysfunction and disabilities than those of female patients. No significant correlations between the burden scores and the age of the caregiver or the patient were seen in this study. However, previous studies from Asia have found that the age of family members is positively associated with their level of burden (Chan et al., 2009; Chien, Chan, \& Morrissey, 2007).

The majority of caregivers in this study were men. A change in traditional gender roles within the family in many cultures has been observed and at present, there is a paucity of research on 
the role, numbers and condition of male caregivers (Chan, 2011). Our study thus contributes to the further understanding of male caregivers in an Asian context.

The duration of the illness did not enter into any significant correlation with the caregivers' burden scores. This is in agreement with the finding of Kate et al. (2013) who observe that it is possible that with increase in duration of illness and duration of treatment, the illness stabilizes and the caregivers perhaps develop adequate coping mechanisms to handle the stress of illness.

In the present study, there were hardly any significant statistical correlates of caregiver burden with their sociodemographic characteristics. This is consistent with the findings of earlier studies (Kate et al., 2013; Tennakoon et al., 2000). The earlier literature shows that families with lower socioeconomic status experienced a higher level of burden (Chien et al., 2007; Ohaeri, 2001) and the respondents in our study also had a low socio-economic profile. The patients' age or the duration of their illness did not enter into any significant correlations with caregiving burden in our study. However patient characteristics such as being female, middle aged and the severity of illness have been found to have an effect on the extent of caregiver burden (Ponangi et al., 2014).

The size of the family has been extracted as a predictor of burden in our study. The negative beta coefficient shows that with increase in family size the experience of caregiver burden is reduced. This indicates that perhaps in larger families, caregiving responsibilities could be shared among members and a higher extent of support is hence available to the primary caregiver. 
Significant positive correlations were seen between the burden and coping scores in this study and the coping scores also emerged as significant predictors of burden in the regression analysis. This finding is in agreement with the literature (Hanzawa et al., 2010; McCann, Lubman, \& Clark, 2011; Nitsche, Koch, \& Kallert, 2010). Three broad types of caregiver coping strategies have been described in the literature. These include appraisal focused coping that is directed toward challenging one's own assumptions, while problem focused coping strategies are directed toward reducing or eliminating a stressor and emotion focused strategies are directed toward changing one's own emotional reaction (Weiten, Lloyd, Dunn, \& Hammer, 2009). A combination of appraisal focused (reframing of the caregiving situation and a passive appraisal of it) and problem focused strategies (mobilising family resources) have been used by caregivers in this study. The use of mixed coping strategies by caregivers of people with schizophrenia has also been reported by earlier studies from India (Aggarwal et al., 2011; Kate et al., 2014; Chadda, Singh, \& Ganguly, 2007). Other studies from India that have evaluated the relationship of burden with coping suggest that the use of emotion focused strategies such as denial are associated with higher burden in caregivers of persons with schizophrenia (Sekharan, Jayashree, \& Sivaprakash, 2001; Rammohan et al., 2002; Creado et al., 2006). Owing to the differences in the assessment scales used in various studies it is difficult to compare findings related to caregiver coping (Grover, Pradyumna, \& Chakrabarti, 2015).

No significant correlations have been obtained between several sociodemographic factors and coping in our study (such as age and gender of the caregivers and the age of the patients). This is generally consistent with the literature that shows no significant statistical associations between socio-demographic characteristics and coping strategies among caregivers of people with schizophrenia (Chadda et al., 2007; Hassan, Mohamed, Elnaser, \& Sayed, 2011; 
Geriani, Kochukarottil, Seemanthini, \& Kanchan, 2015). However it was seen in this study that while spouses tend to reframe their situation or seek spiritual support, parents tend to mobilise family resources to enhance their coping. Other studies from India report that female caregivers use problem focused and support seeking strategies more often, and avoidance to a lesser extent (Nehra et al., 2005), while married caregivers more often seek spiritual help (Chakrabarti \& Gill, 2002). In our study we found that caregivers of female patients tend to seek more spiritual support in terms of their coping strategy. It has been reported that increased religiosity is associated with less depression, better self-esteem and better self-care in caregivers (Murray-Swank et al., 2006).

In terms of social support, the negative correlation with the total burden scores and positive correlation with the coping scores in our study indicates that support is crucial for families to alleviate the burden that they experience and to enhance their coping. Further, the social support score emerged as a significant predictor of family burden and this is in agreement with an earlier Asian study (Chien et al., 2007) that elicited social support as the best predictor of caregiver burden. The crucial role played by social support vis-à-vis the burden experienced by caregivers is in agreement with the Western literature (Magliano et al., 2005; Goncalves-Pereira, Xavier, van Wijngaarden, Papoila, Schene, \& Caldas-de-Almeida, 2013) and also with other studies from India (Kate et al., 2013). Seeking social support as a coping strategy has also been identified in another study from India (Aggarwal et al., 2011).

The negative correlation of the patients' negative symptoms with social support is not really surprising as many of the negative symptoms (such as blunted affect, emotional withdrawal, poor rapport, apathetic social withdrawal) are not conducive for social interaction. This is also in agreement with other studies that have examined the relation between patient's 
negative symptoms and perceived social support by caregivers (Razali \& Hariani, 2015). The positive correlation obtained between the social support and coping scores also underline its importance in enhancing or limiting the coping effectiveness of the caregivers.

\section{Limitations of the study}

The study was cross-sectional in nature and does not capture the dynamics of burden, coping and social support as these variables could tend to change over time along with the symptoms of the patient.

Further the study was conducted with a rural population from a low socio-economic and educational background and hence the scope for generalization of the findings is rather limited.

Aspects relating to the personality of the caregivers such as resilience and the positive experience of caregiving in terms of satisfaction have not been incorporated in our study. Further, the study group respondents were drawn from an in-patient hospital setting and the results could be different for those in out-patient or domiciliary care programs. In spite of these limitations an important strength of this study in our opinion is that we have contrasted the key variables with a reference group of caregivers, which through statistical analysis has helped in generating comparative results.

\section{Implications for intervention:}

The findings of this study indicate that caregivers of patients with schizophrenia also merit intervention in the light of greater burden, lower social support, and coping deficits manifested in them. In the light of these findings, it would be useful to briefly draw from the intervention literature to outline how caregivers could benefit from supportive intervention strategies that seek to decrease their burden levels and enhance social support and coping. 
Previous studies have indicated that many family caregivers did not have the knowledge and skills necessary to take on the responsibilities of caregiving for relatives with schizophrenia and consequently they are unable to cope with a considerable amount of their caring roles and responsibilities (Chan et al., 2009). It thus becomes important to engage with caregivers to provide information about issues relating to schizophrenia such as its symptoms, progressive nature, importance of treatment continuity and other areas that could promote better patient management. Individual or small group work to provide psychoeducation could be useful and the caregiving intervention literature endorses the benefits of such an approach. While some studies vouch for the effectiveness of individual based interventions (Sharif, Shaygan, \& Mani, 2012), others show that group sessions have similar levels of effectiveness (Barrio \& Yamada, 2012; Koolaee \& Etemadi, 2010).

In terms of intervention with caregivers of people with schizophrenia, two major models have been empirically tested in the West namely, the behavioural family management model and the family psychoeducational model (Chakrabarti, 2011). A subset of the family education model is the consultation model, in which individual families meet periodically with a professional to receive information, advice, or support according to their needs and has been suggested to be a more appropriate model for Indian families (Chakrabarti, 2016). Interventions that place an emphasis on ongoing contact and medication adherence while offering emotional and practical support, and which rely on non-specialist professionals for delivery are more likely to succeed in the Indian context (Kulhara, Chakrabarti, Avasthi, Sharma, \& Sharma, 2009; Chakrabarti, 2011).

Four key areas have been outlined by Magliano et al. (2005) especially relating to caregiving in schizophrenia. These are: (a) the management of caregivers' psychological reactions to the 
illness; (b) the provision of information on the nature, course and outcome of the illness; (c) training for caregivers in the management of symptoms; and (d) the reinforcement of the caregivers' social networks. It has also been suggested that adequate information regarding the illness to both caregiver and patient and their involvement in the care plan, access to better treatment including medication and psychosocial interventions, ongoing support for both and measures to minimize the impact of stigma are ways to facilitate coping and ease burden (Awad \& Voruganti, 2008).

Social support appears to be an important factor to decrease family burden and enhance coping. Helping families to maintain and enhance a supportive social network could be a useful means to reduce family caregivers' burden with persons with schizophrenia (Chan, 2011). A randomized controlled trial of a mutual support group for family caregivers of patients with schizophrenia shows beneficial outcomes for family caregivers that go beyond those provided by routine family support and also improve family functioning and decrease levels of burden (Chien, Norman, \& Thompson, 2004). It has been suggested that the consultation model, in which individual families meet periodically with a professional involved in the patient's treatment to receive information, advice, or support according to their needs could be a more appropriate model for Indian families (Chakrabarti, 2016). Family caregivers should be encouraged to attend support groups that provide information about mental illness, treatment, coping skills and opportunities to learn from the experiences of others who have similar caregiving experiences (Hsiao, 2010). Organising such supportive networks could besides enabling caregivers to vent their frustrations and anxieties in a safe environment may also facilitate experience sharing and learning from mutual experience. 


\section{Conclusion}

This study compared caregivers of people with schizophrenia (study group) with those receiving treatment for general medical conditions (reference group). Findings revealed significantly high burden and lower coping and social support in caregivers of people with schizophrenia. Significant correlations were seen among these variables. No significant correlations were seen in terms of the socio-demographic characteristics of the respondents and the burden experienced by them. Coping, social support and the family size were extracted as predictors of burden experienced by these caregivers. This indicates that caregiving burden is reduced when there are more people to support the person with mental illness. Interventions aimed at increasing social support and coping efficacy have been outlined in this article in the light of the findings of this study. 


\section{References}

Adeosun, I.I. (2013). Correlates of Caregiver Burden among Family Members of Patients with Schizophrenia in Lagos, Nigeria. Schizophrenia Research and Treatment, Article ID 353809, 7 pages. doi:10.1155/2013/353809

Aggarwal, M., Avasthi, A., Kumar, S. \& Grover, S. (2011). Experience of caregiving in India: A study from India. International Journal of Social Psychiatry, 57, 224-236.

Ampalam, P., Gunturu, S., \& Padma, V. (2012). A comparative study of caregiver burden in psychiatric illness and chronic medical illness. Indian Journal of Psychiatry, 54, 239-243.

Awad, A.G., \& Voruganti, L.N. (2008). The burden of schizophrenia on caregivers: A review. Pharmacoeconomics, 26, 149-162. 
Barrio, C., \& Yamada, A.M. (2010). Culturally based intervention development: The case of latino families dealing with schizophrenia. Research on Social Work Practice, 20, 483-492.

Brinda, E.M., Anto P Rajkumar, A.P., Enemark, U., Attermann, J., \& Jacob, K. S. (2014). Cost and burden of informal caregiving of dependent older people in a rural Indian community. BMC Health Services Research, DOI: 10.1186/1472-6963-14-207

Caqueo-Urizar, A., Gutierrez-Moldonado, J., \& Miranda-Castillo, C. (2009). Quality of life in caregivers of patients with schizophrenia: a literature review. Health and Quality of Life Outcomes, 7, 84.

Caqueo-Urízar, A., Miranda-Castillo, C., Giráldez, S.L., Maturana, S.L., Pérez, M.R., \& Tapia, F.M. (2014). An updated review on burden on caregivers of schizophrenia patients, Psicothema, 26, 235-243. doi: 10.7334/psicothema2013.86

Caudle, P. (1993). Providing culturally sensitive health care to Hispanic clients. Nurse Practitioner, 28, 40-51.

Chadda, R.K., Singh, T.B., \& Ganguly, K. K. (2007). Caregiver burden and coping: A prospective study of relationship between burden and coping in caregivers of patients with schizophrenia and bipolar affective disorder. Social Psychiatry and Psychiatric Epidemiology, 42, 923-930.

Chakrabarti, S., \& Gill, S. (2002). Coping and its correlates among caregivers of patients with bipolar disorder: A preliminary study. Bipolar Disorder, 4, 50-60. 
Chakrabarti, S. (2011). Family interventions in schizophrenia: Issues of relevance for Asian countries. World Journal of Psychiatry, 11, 4-7.

Chakrabarti, S. (2016). Research on Family Caregiving for Mental Illness in India and its Impact on Clinical Practice: Are we Doing Enough to Help Families? Indian Journal of Social Psychiatry, 32, 19-24.

Chan S. W. (2011). Global perspective of burden of family caregivers for persons with schizophrenia. Archives of Psychiatric Nursing, 25, 339-349.

doi: 10.1016/j.apnu.2011.03.008.

Chan, S.W., Yip, B., Tso, S., Cheng, B.S., \& Tam, W. (2009). Evaluation of a psychoeducation program for Chinese clients with schizophrenia and their family caregivers. Patient Education and Counseling, 75, 67-76.

Chan, S., \& Yu, I. W. (2004). The quality of life of clients with schizophrenia. Journal of Advanced Nursing, 45, 72-83.

Chandrasekharan, R., Sivaprakash, B., \& Jayestri, S. R. (2002). Coping strategies of the relatives of schizophrenic patients. Indian Journal of Psychiatry,44, 9-13.

Cheng, L.Y. \& Chan, S. (2005). Psychoeducation program for Chinese family carers of members with Schizophrenia. The Western Journal of Nursing Research, 27, 585-599.

Chien, W.T., Chan, S. W., \& Morrissey, J. (2007). The perceived burden among Chinese family caregivers of people with schizophrenia. Journal of Clinical Nursing, 16, 1151-1161. 
Chien, W-T., Norman, I., \& Thompson, D. R. (2004). A randomized controlled trial of a mutual support group for family caregivers of patients with schizophrenia. International Journal of Nursing Studies, 41, 637-649.

Creado, D.N., Parkar, S.R., \& Kamath, R.M. (2006). A comparison of the level of functioning in chronic schizophrenia with coping and burden in caregivers. Indian Journal of Psychiatry, 48, 27-33.

Cutrona, C. E., \& Russell, D. W. (1987). The provisions of social relationships and adaptation to stress. In W. H. Jones \& D. Perlman (Eds.), Advances in personal relationships (Vol. 1, pp. 37-67). Greenwich, CT: JAI Press Inc

Ganguly, K., Chadda, R. K., \& Singh, T. B. (2010). Caregiver burden and coping in schizophrenia and bipolar disorder: A Qualitative Study. American Journal of Psychiatric Rehabilitation, 13, 126-142.

Gater, A., Rofail,D., Tolley,C., Marshall, C., Abetz-Webb, L., Zarit, S.H., \& Berardo, C.G. (2014). Sometimes It's Difficult to Have a Normal Life: Results from a Qualitative Study Exploring Caregiver Burden in Schizophrenia. Schizophrenia Research and Treatment, 368215. http://dx.doi.org/10.1155/2014/368215

Geriani, D., Kochukarottil,S.B.S., Seemanthini, S., \& Kanchan, T. (2015). Burden of Care on Caregivers of Schizophrenia Patients: A Correlation to Personality and Coping. Journal of Clinical and Diagnostic Research, 9, VC01-VC04. 
Goncalves-Pereira, M., Xavier, M., van Wijngaarden, B., Papoila, A.L., Schene, A.H., \& Caldas-de-Almeida, J.M. (2013). Impact of psychosis on Portuguese caregivers: A crosscultural exploration of burden, distress, positive aspects and clinical-functional correlates. Social Psychiatry and Psychiatric Epidemiology, 48, 325-335.

Grover, S., Pradyumna, \& Chakrabarti, S. (2015). Coping among the caregivers of patients with schizophrenia. Industrial Psychiatry Journal, 24, 5-11.

Guarnaccia, P., \& Parra, P. (1996). Ethnicity, social status, and families' experiences of caring for a mentally ill family member. Community Mental Health Journal, 32, 243-260.

Gülseren, L., Çam, B., Karakoç, B., Yiğit, T., Danaci, A.E., Çubukçuoğlu, Z., ... Mete, L. (2010). The Perceived Burden of Care and its Correlates in Schizophrenia. Turkish Journal of Psychiatry, 21, 203-212.

Hanzawa, S., Bae, J.K., Tanaka, H., Bae, Y.J., Tanaka, G., Inadomi, H., ... Ohta, Y. (2010). Caregiver burden and coping strategies for patients with schizophrenia: Comparison between Japan and Korea. Psychiatry and Clinical Neurosciences, 64, 377-86.

Hassan, W.A.N., Mohamed, I.I., Elnaser, A.E.A., \& Sayed, N. E. (2011). Burden and coping strategies in caregivers of schizophrenic patients. Journal of American Science, 7, 802-811. 
Isaac, V., Stewart, R., \& Krishnamoorthy, E. S. (2011). Caregiver Burden and Quality of Life of Older Persons with Stroke: A Community Hospital Study in South India. Journal of Applied Gerontology, 30, 5, 643-654.

Janardhana, N., Raghunandan, S., Naidu, D. M., Saraswathi, L., \& Seshan, V. (2015). Care Giving of People with Severe Mental Illness: An Indian Experience. Indian Journal of Psychological Medicine, 37, 184-194. http://doi.org/10.4103/0253-7176.155619

Jayakumar, C., Jagadheesan, K., \& Verma, A.N. (2002). Caregiver's burden: A comparison between obsessive compulsive disorder and schizophrenia. Indian Journal of Psychiatry, 44, $337-42$.

Jenkins, J.H., \& Schumacher, J.G. (1999). Family burden of schizophrenia and depressive illness. British Journal of Psychiatry, 174, 31-38.

Kate, N., Grover, S., Kulhara, P., \& Nehra, R. (2013). Relationship of caregiver burden with coping strategies, social support, psychological morbidity, and quality of life in the caregivers of schizophrenia. Asian Journal of Psychiatry, 6, 380-368.

Kate, N., Grover, S., Kulhara, P., \& Nehra, R. (2014). Relationship of quality of life with coping and burden in primary caregivers of patients with schizophrenia. International Journal of Social Psychiatry, 60, 107-116.

Kay, S.R., Fiszbein, A., \& Opler, L. A. (1987). The positive and negative syndrome scale (PANSS) for schizophrenia. Schizophrenia Bulletin, 13, 261-276. 
Koolaee, A.K., \& Etemadi, A. (2010). The outcome of family interventions for the mothers of schizophrenia patients in Iran. International Journal of Social Psychiatry, 56, 634-646.

Kulhara, P., Chakrabarti, S., Avasthi, A., Sharma, A., \& Sharma, S. (2009).

Psychoeducational intervention for caregivers of Indian patients with schizophrenia: A randomised-controlled trial. Acta Psychiatrica Scandinavica, 119, 472-483.

Kumar, S., \& Mohanty, S. (2007). Spousal Burden of Care in Schizophrenia. Journal of the Indian Academy of Applied Psychology, 33, 189-194.

Lasebikan, V. O., \& Ayinde, O. O. (2013). Family burden in caregivers of schizophrenia patients: Prevalence and socio-demographic correlates. Indian Journal of Psychological Medicine, 35, 60-66.

Lowyck, B., De Hert, M., Peeters, E., Wampers, M., Gilis, P., \& Peuskens, J. (2004). A study of the family burden of 150 family members of schizophrenic patients. European Psychiatry 2 19, 395-401.

Lukhmana, S., Bhasin, S.K., Chhabra, P., \& Bhatia, M.S. (2015). Family caregivers' burden: A hospital based study in 2010 among cancer patients from Delhi. Indian Journal of Cancer, $52,1,146-151$.

McCann, T.V., Lubman, D.I., \& Clark, E. (2011). First-time primary caregivers' experience of caring for young adults with first-episode psychosis. Schizophrenia Bulletin, 37, 381-388. 
McCubbin, H., Larson, A., \& Olson, D. (1987). F-COPES Family Crisis Oriented Personal Scales. In H. McCubbin \& A. Thompson (Eds.), Family assessment inventories for research and practice. Madison, WI: University of Wisconsin, Madison

Magliano, L., Fiorillo, A., Malangone, C., Marasco, C., Guarneri, M., \& Maj, M. (2003). The effect of social network on burden and pessimism in relatives of patients with schizophrenia. American Journal of Orthopsychiatry, 73, 302-309.

Magliano, L., Fiorillo, A., De Rosa, C., Malangone, C., \& Maj, M. (2005) Family burden in long-term diseases: a comparative study in schizophrenia vs. physical disorders. Social Science and Medicine, 61, 313-22.

Mandal, P., Prakash, S., \& Sagar, R. (2014). Primary caregivers of schizophrenia outpatients: burden and its correlates. Delhi Psychiatry Journal, 17, 343-348.

Martens, L., \& Addington, J. (2001). The psychological well-being of family members of individuals with schizophrenia. Social Psychiatry and Psychiatric Epidemiology, 36, 128133.

Math, S. B., Chandrashekar, C. R., \& Bhugra, D. (2007). Psychiatric epidemiology in India. Indian Journal of Medical Research, 126, 183-92.

McCann, T. V., Lubman, D.I., \& Clark, E. (2011). First-time primary caregivers' experience of caring for young adults with first-episode psychosis. Schizophrenia Bulletin, 37, 381-388. 
Murray-Swank, A. B., Lucksted, A., Medoff, D. R., Yang, Y., Wohlheiter, K., \& Dixon, L. B. (2006). Religiosity, psychosocial adjustment, and subjective burden of persons who care for those with mental illness. Psychiatric Services, 57, 361-365.

Nehra, R., Chakrabarti, S., Kulhara, P., \& Sharma, R. (2005). Caregivercoping in bipolar disorder and schizophrenia - A reexamination. Social Psychiatry and Psychiatric Epidemiology, 40, 329-36.

Nitsche, I., Koch, R., \& Kallert, T. (2010). Which factors infl uence the psychological distress among relatives of patients with chronic functional psychoses? An exploratory study in a community mental health care setting. Journal of Public Health, 18, 105-117.

Ohaeri, J. U. (2001). Caregiver burden and psychotic patient's perception of social support in Nigerian setting. Social Psychiatry and Psychiatric Epidemiology, 36, 86-93.

Ponangi, C. D., Thatisetti, V. P. K., \& Dronanmraju, P. B. (2014). Caregiver burden in patients with schizophrenia. AP Journal of Psychological Medicine, 15, 117-121.

Prafulla, S., Murthy, S. K., \& Ramaprasad, D. (2010). Family Burden and rehabilitation Needs of Beneficiaries of a Rural Mental Health Camp in a Southern State of India. International Journal of Psychosocial Rehabilitation, 15, 5-11.

Provencher, H. L., \& Mueser, K. T. (1997). Positive and negative symptom behaviors and caregiver burden in the relatives of persons with schizophrenia. Schizophrenia Research, 26, 71-80. 
Rammohan, A., Rao, K., \& Subbakrishna, D.K. (2002). Burden And Coping In Caregivers Of Persons With Schizophrenia. Indian Journal of Psychiatry, 44, 220-227.

Razali, S. M., \& Hariani, I. (2015). Caregiving Experience and Social Support in Patients with Schizophrenia. International Medical Journal, 22, 263-267.

Reine, G., Lancon, C., Simeoni, M. C., Duplan, S., \& Auquier, P. (2003). Caregiver burden in relatives of persons with schizophrenia: An overview of measure instruments. Encephale, $29,137-147$.

Roick, C., Heider, D., Toumi, M., \& Angermeyer, M. C. (2006). The impact of caregivers' characteristics, patients' conditions and regional differences on family burden in schizophrenia: A longitudinal analysis. Acta Psychiatrica Scandinavica, 114, 363-374.

Rose, L.E., Mallinson, R.K., \& Gerson, L.D. (2006). Mastery, Burden, and Areas of Concern Among Family Caregivers of Mentally Ill Persons. Archives of Psychiatric Nursing, 20, 4151.

Saunders, J. (1999). Family functioning in families providing care for a family member with schizophrenia. Issues in Mental Health Nursing, 20, 95-113.

Schene, A.H., van Wijngaarden, B., Koeter, M.W.J. (1998). Family caregiving in schizophrenia: domains and distress. Schizophrenia Bulletin, 24, 609-618. 
Schulz, R. \& Sherwood, P.R. (2008). Physical and Mental Health Effects of Family Caregiving. American Journal of Nursing, 108(9 Suppl), 23-27.

doi: 10.1097/01.NAJ.0000336406.45248.4c

Sethabouppha, H., \& Kane, C. (2005). Caring for the seriously mentally ill in Thailand: Buddhist family caregiving. Archives of Psychiatric Nursing, 19, 44-57.

Sharif, F., Shaygan, M., \& Mani, A. (2012). Effect of a psycho-educational intervention for family members on caregiver burdens and psychiatric Symptoms in patients with schizophrenia in Iran. BMC Psychiatry, 12, 48. http://www.biomedcentral.com/1471$244 \mathrm{X} / 12 / 48$

Sekharan, R.C., Jayshree, S.R., \& Sivaprakash, B. (2001). Family burden and coping strategies in relatives of schizophrenic patients. Indian Journal of Psychiatry, 43, 36.

Stanley, S., Mettilda, G. B., \& Bhakyalakshmi, S. (2015). Mental health status and perceived burden in caregiving spouses of persons with psychotic illness (A study from India). Social Work in Mental Health. DOI:10.1080/15332985.2015.1064508

Talwar, P., \& Matheiken, S.T. (2010). Caregivers in schizophrenia: A cross cultural perspective. Indian Journal of Psychological Medicine, 32, 29-33.

Tennakoon, L., Fannon, D., Doku, V., O'Ceallaigh, S., Soni, W., Santamaria, M., ... Sharma, T. (2000). Experience of caregiving: relatives of people experiencing a first episode of psychosis. The British Journal of Psychiatry, 177, 529-533. doi: 10.1192/bjp.177.6.529 
Thara, R., Kamath, S., \& Kumar, S. (2003). Women with schizophrenia and broken marriages-doubly disadvantaged? Part II: Family perspective. International Journal of Social Psychiatry, 49, 233-240.

Thara, R., Padmawati, R., Kumar, S., \& Srinivasan, L. (1998). Burden assessment scheduleinstrument to assess burden on caregivers of chronic mentally ill. Indian Journal of Psychiatry, 40, 21-29.

Thara, R., \& Srinivasan, T. N. (2000). How stigmatising is schizophrenia in India? International Journal of Social Psychiatry, 46,135-141.

Ukpong, D. (2012). Burden and Psychiatric disorders among Nigerian family caregivers of schizophrenia patients: the role of positive and negative symptoms. Turkish Journal of Psychiatry, 23, 40-45.

van Driessche, A., Jotheeswaran, A. T., Murthy, G. V. S., Pilot, E., Sagar, J., Pant, H., Singh, V., \& Babu, D.P.K. (2014). Psychological well-being of parents and family caregivers of children with hearing impairment in south India: Influence of behavioural problems in children and social support. International Review of Psychiatry, 26, 4, 500-507.

van Wijngaarden, B., Schene, A., Koeter, M., Becker, T., Knapp, M., Knudsen, H.C., ... EPSILON study group (2003). People with schizophrenia in five countries: conceptual similarities and intercultural differences in family caregiving. Schizophrenia Bulletin, 29, $573-586$. 
Weiten, W., Lloyd, M.A., Dunn, D. S., \& Hammer, E. Y. (2009). Psychology Applied to Modern Life: Adjustment in the $21^{\text {st }}$ Century. 9th ed. Belmont, CA: Wadsworth/Cengage.

Wolthaus, J., Dingemans, P., Schene, A., Linszen, D. H., Wiersma, D., Van Den Bosch, R. J., ... Hijman, R. (2002). Caregiver burden in recent-onset schizophrenia and spectrum disorders: the influence of symptoms and personality traits. Journal of Nervous and Mental Disease, 190, 241- 247.

World Health Organisation (2016).

http://www.who.int/mental_health/management/schizophrenia/en/ (Accessed 20.03.2016).

Zarit, S.H., Todd, P.A., \& Zarit, J. M. (1986). Subjective burden of husbands and wives as caregivers: a longitudinal study. Gerontologist, 26, 260-266. 